\title{
EXPERIÊNCIA: PAPEL DO PROTOCOLO DE ENFEMAGEM NO PROCESSO DE ACOLHIMENTO E PRIMEIRA CONSULTA, PARA ZELAR AS FILAS NA ATENÇÃo PRIMÁRIA À SAÚDE, NO MUNICÍPIO DE JARAGUÁ DO SUL - SC
}

Flávio Alberto de Andrade Goulart, Júlio Manuel Suarez Jimenez, Silvia Regina Bonatto Curty, Priscila Steffani e Rosana Mara da Silva

\section{RESUMO}

Este artigo descreve a experiência de Jaraguá do Sul, Santa Catarina, visando reduzir filas de espera nas unidades de saúde do município mediante a elaboração e aplicação de um Protocolo de Enfermagem.

Palavras-chave: Atenção Primária à Saúde; Acesso; Prêmio APS.

\section{ABSTRACT}

This article describes the experience of Jaraguá do Sul, Santa Catarina, aiming to reduce waiting lines at health units in the city through the development and application of a Nursing Protocol.

Keywords: Prmary Health Care; Access; PHC Prize.
Revista da Rede APS 2020

Publicada em: 04/09/2020

DOI:10.14295/aps.v2i3.152

Flávio Alberto de Andrade Goulart

(Organização Pan-Americana de Saúde)

Júlio Manuel Suarez Jimenez (Organização Pan-Americana de Saúde)

Silvia Regina Bonatto Curty (Secretaria Municipal da Saúde de Jaraguá do Sul, Santa Catarina)

Priscila Steffani

(Secretaria Municipal da Saúde de Jaraguá do Sul)

Rosana Mara da Silva (Secretaria Municipal da Saúde de Jaraguá do Sul, Santa Catarina)

Correspondência para:

Flávio Alberto de Andrade Goulart goulart.fa@gmail.com

Artigo premiado no concurso "Prêmio APS Forte para o SUS Acesso Universal" - selecionado por uma equipe de jurados especiais designados pela Organização Pan-Americana da Saúde no Brasil (OPAS) no Brasil. 


\section{VISÃO GERAL E CONTEXTO}

Jaraguá do Sul é um município situado a Norte/Nordeste do estado de Santa Catarina, região Sul do Brasil, com população estimada, para 2019, em 177,7 mil habitantes, com um Índice de Desenvolvimento Humano Municipal (IDHM) de 0,803, o que coloca a cidade em oitava posição no ranking estadual e 34a posição no ranking nacional. Suas origens remontam aos meados do século XIX e derivam de um dote de terras recebido pela Princesa Isabel, quando se casou com Gastão de Orléans, o Conde d'Eu. Alguns anos mais tarde essas terras foram exploradas por pelas famílias alemãs Krohne e Hillbrecht, repetindo a tendência que se estabeleceu para o estado de SC e parte da região Sul do Brasil. Além dos alemães, a cidade também tem representações étnicas de húngaros, poloneses e italianos. Sua manifestação cultural mais expressiva, derivada da colonização alemã, é a chamada Schützenfest (Festa dos Atiradores).

No município de Jaraguá do Sul reside uma das cinco maiores forças econômicas de Santa Catarina, logo atrás da capital Florianópolis, além de Joinville, Blumenau e Itajaí, sendo também o terceiro núcleo industrial do estado e sede de algumas das maiores empresas nacionais nos setores de metalurgia, mecânica e de confecções, destacando-se também empresas do ramo de tecnologia e prestação de serviços. É especialmente conhecida como Capital Nacional da Malha. Grande parte das empresas estabelecidas em Jaraguá do Sul é de origem familiar.

A rede de saúde do município, no campo da Atenção Básica, conta 27 Unidades Básicas de Saúde, com um corpo técnico constituído por 27 enfermeiros e 26 médicos, com carga horária de 40 horas semanais, além de alguns outros profissionais de nível superior com cargas horárias menores. Em termos de produção, foram realizados na rede municipal, nos primeiros oito meses de 2019, cerca de 36 mil consultas, com $51 \%$ de cobertura pela
Estratégia Saúde da Família. Além de tal estrutura, existem dois serviços de Pronto Atendimento (PAMA) e dois hospitais.

\section{MOTIVAÇÕES E ESTRATÉGIAS}

O presente projeto foi pensado com o intuito de reduzir filas de espera nas unidades de saúde do município, mediante a elaboração e aplicação de um Protocolo de Enfermagem, abrindo caminho para a consulta com o enfermeiro na Atenção Básica em Saúde. O problema em foco se via agravado pelo fato de que boa parte de tal demanda se referia ao retorno de exames, à avaliação de problemas de baixa complexidade, além da renovação de receitas. A iniciativa teve início em julho de 2018, mas é considerada pelos propositores como já em estágio avançado de execução.

O grande fator motivador da presente iniciativa, qual seja o de reduzir as filas de espera na Atenção Básica, representa um desafio comum entre os gestores da saúde, não só locais, como do restante do estado e mesmo do país. Neste aspecto, o fortalecimento das atribuições dos profissionais da enfermagem constitui uma opção adotada em muitos países do mundo, de forma a garantir resolutividade $e$ sustentabilidade dos sistemas universalizados de saúde, entre os quais se inclui o SUS brasileiro, no qual estratégias assemelhadas têm ganhado, nos últimos anos, grande prioridade e visibilidade.

A questão das filas de espera é bem definida e mensurada na cidade, que registrava oficialmente, só no mês de novembro de 2018, em torno de 15 a 16 mil consultas reprimidas em todo o conjunto de unidades básicas de saúde, acarretando, naturalmente, marcante insatisfação e reclamação dos usuários. Destas consultas reprimidas, 12,7 mil eram de primeira consulta e 2,7 mil de retorno.

Assim é que se buscou a atualização e a implantação de um protocolo de enfermagem, dentro de um movimento mais amplo, executado também por outras secretarias municipais de saúde, com eventual apoio dos conselhos regionais de Enfermagem, voltado a ampliar o acesso dos usuários nas unidades 
básicas de saúde, além de proporcionar mais nitidez ao papel e à identidade do pessoal de enfermagem na Atenção Básica.

Inspirada na experiência já desenvolvida na capital, Florianópolis, a SMS local partiu para a elaboração de um Protocolo de Enfermagem próprio, de forma a garantir maior segurança para a atuação dos enfermeiros da rede municipal e reduzir as filas de espera no nível da porta de entrada do sistema local de saúde. Desta forma, foram incorporados como rotinas de trabalho das unidades da rede, não só a consulta, como também a prescrição de exames e medicamentos essenciais, além da formalização do acolhimento nas unidades de saúde, com participação e liderança dos profissionais da enfermagem, a partir de novembro de 2018.

As estratégias de implementação das medidas propostas se iniciaram, ainda em 2018, pela constituição de uma comissão formada por enfermeiros da rede municipal, para estudar e tentar compreender as condições locais responsáveis por tais filas para consulta na Atenção Básica, estimando as demandas em termos de primeira consulta e retorno. Após tal movimento é que se passou à elaboração de um protocolo com foco na atuação da enfermagem, com definições a respeito da consulta específica na Atenção Básica, prescrição de exames e medicamentos essenciais, bem como estruturação de processo de acolhimento. Tal comissão teve o apoio do COREN-SC, além da gestão da Secretaria Municipal de Saúde de Florianópolis.

Ficou desde então definido que os profissionais de enfermagem, munidos dos referidos protocolos, realizariam consultas relativas a acolhimento e manejo de condições como hipertensão arterial, diabetes, tabagismo, obesidade, fatores associados a doenças cardiovasculares, infecções sexualmente transmissíveis, tuberculose e dengue, além de programas específicos de saúde da mulher e do adulto. Através de tais protocolos os enfermeiros passariam a realizar a prescrição de exames e a requisição de medicamentos, dentro do quadro de condições acima.

Foi simultaneamente definido um fluxograma de implantação das novas medidas, instituindo-se, para tanto, uma Comissão de Implantação, Monitoramento e Avaliação dos Protocolos. A proposta foi então apresentada para apreciação da comunidade, não só na Câmara de Vereadores do município, mas também em reuniões multidisciplinares e nas mídias sociais, culminando com a apresentação no Conselho Municipal de Saúde. Somente após tais procedimentos de publicitação foi iniciada a implantação dos referidos protocolos nas Unidades Básicas de Saúde.

\section{RESULTADOS}

Em termos de resultados, já em maio de 2019 foram observadas mudanças significativas em consequência das medidas iniciadas alguns meses antes, como foi o caso de ter sido "zerada" a fila das primeiras consultas para a Atenção Básica. Isso foi possível graças a um conjunto planejado de medidas associadas ao referido protocolo, entre as quais a realização de mutirões de atendimento e o direcionamento das agendas para o atendimento das demandas espontâneas dos usuários (70\%) e para o atendimento da demanda programada (30\%), obedecendo orientações do Ministério da Saúde.

Assim, se em novembro de 2018 o município apresentava uma fila para primeira consulta de 12.765 pessoas e para retorno de 2.745 em seu conjunto de unidades básicas de saúde do município, já no mês de maio de 2019 , foram zeradas tais as filas de espera, o que foi possível graças à organização de uma ação formal de acolhimento centrado na figura do 
profissional enfermeiro, com exercício autorizado de prescrição e encaminhamento aos médicos somente de pacientes com necessidade específica de atendimento por este profissional.

Na verdade, já no início de dezembro de 2018, um levantamento preliminar demonstrou que as filas tiveram redução de $75 \%$ para primeira consulta, como efeito das medidas de implantação dos referidos protocolos, bem como dos mutirões de atendimento.

As consultas de enfermagem na rede de APS do município também tiveram incremento expressivo. Considerando apenas os períodos de janeiro a agosto de 2018 e 2019, ou seja, antes e após a implantação dos Protocolos da Enfermagem, houve um salto de 15,1 mil para 32,8 mil consultas, um acréscimo de $116 \%$ de um ano para outro.

Não consta ter ocorrido aumento de custos com a implementação do processo, já que o mesmo consistiu basicamente em reorganização de processos de trabalho, através da já referida comissão de implantação. Fator a ser considerado como positivo foi, também, a intensiva capacitação dos enfermeiros, junto com o apoio institucional do Coren-SC e da Secretaria Municipal de Saúde de Florianópolis.

\section{DISCUSSÃO}

A entrevista com os atores locais, realizada pela equipe de consultores da OPAS permitiu delinear os marcos principais de tal experiência, em termos de seus fatores facilitadores e estratégias empregadas, suas dificuldades e desafios, bem como lições $e$ insights despertados.

\section{FATORES FAVORECEDORES}

Por outro lado, houve fatores facilitadoras relevantes, como, por exemplo, o apoio externo angariado pela comissão de implantação, que incluiu organismos da comunidade, entidades profissionais, agentes políticos e usuários organizados. Neste aspecto, a adesão dos usuários foi fundamental, mesmo que alguns desses temessem, no princípio pelo menos, que a iniciativa em curso pudesse retardar o período de espera para conseguirem a almejada consulta com o médico.

Podem ser listados, ainda, como fatores que contribuíram para o bom desempenho da iniciativa: a condução e a liderança exercida pela Enfermagem, apoiada por uma comissão com representação ampla dos serviços; os esforços de convencimento particularmente dirigidos a usuários e lideranças comunitárias; o adequado planejamento da implantação, de forma gradual, participativa e aberta a correções de rumo, além de apoio político negociado.

Destacam-se algumas das estratégias de implementação empregadas, sintonizadas com as boas práticas de gestão existentes no horizonte dos serviços de saúde, sejam públicos ou privados. Assim, podem ser citadas: a clareza em relação ao potencial de empoderamento e reforço identitário do pessoal da enfermagem, sob a liderança de tal categoria; a busca de envolvimento ampliado de atores sociais, internos ou externos aos serviços e ao órgão gestor; o processo de implementação realizado mediante procedimentos de focos múltiplos, além da efetivação dos protocolos; a utilização de referencial teórico consequente de planejamento; o incrementalismo da implementação, sem perder de vista o alcance de um todo de $100 \%$ dos serviços; o vislumbre de serviços com componentes pedagógicos, traduzido pela ideia de "Unidades Escola" e até mesmo a associação com Residência Médica no processo.

\section{DIFICULDADES E OBSTÁCULOS}

As maiores dificuldades foram corporativas, embora tenham sido contornadas com relativo sucesso. Um secretário de saúde, depois afastado, resistiu à ideia, da mesma forma que a corporação médica, como seria esperado, dada a verdadeira quebra de monopólio que a proposta incluía. Certo temor de "excesso de trabalho e responsabilidades", por parte de algumas categorias profissionais também foi situação relatada como obstáculo. 
Restrições burocráticas, por exemplo, na demora de efetivação de pessoal concursado e falta de ACS na rede também tiveram seu peso.

\section{LIÇÕES APRENDIDAS}

A capacidade de reprodução da experiência dependeria, fundamentalmente, de decisão política local, que no caso de Jaraguá do Sul foi muito relevante. Uma vez garantido tal apoio, outros fatores devem ser também considerados relevantes, tendo estado presentes no caso em foco. São eles: a constituição de liderança boa e firme; o convencimento democrático e profundo dos atores sociais; a existência de comunicação "boca a boca" entre usuários bem informados; a busca da qualidade nas ações, longe de um mero "mais do mesmo"; o empoderamento do pessoal da enfermagem; o estabelecimento de setor de acolhimento formalizado nas unidades; a mensuração criteriosa de resultados e impactos, entre outros.

Em suma, nas palavras dos próprios proponentes da experiência, através desta iniciativa se demonstra uma transformação da realidade local no fluxo de atendimento dentro das Unidades Básicas de Saúde, permitindo ao usuário do SUS ter sua demanda atendida, a partir da ótica da multidisciplinariedade e analisando a demanda de forma interdisciplinar, no compartilhamento do cuidado a saúde. Ao se analisar a influência regional, denota-se a utilização do processo de implantação na realidade da macrorregião, permitindo aos municípios próximos realizar trocas acerca do processo de implantação e efetivação.

\section{REFERÊNCIA}

- Organização Pan-Americana da Saúde. Ampliação do papel dos enfermeiros na atenção primária à saúde. Washington, D.C.: OPAS; 2018 